\title{
Addison disease and normocalcemic primary hyperparathyroidism in a dog with multiple endocrine neoplasia
}

\author{
Elber Alberto Soler Arias ${ }^{1, *}$, Victor Alejandro Castillo ${ }^{1}$ and Roberto Hector Trigo ${ }^{2}$ \\ ${ }^{1}$ Hospital Escuela, Unidad de Endocrinología, Área de Clínica Médica de Pequeños Animales, Fac. de Ciencias \\ Veterinarias, UBA, Av. Chorroarín 280, Ciudad Autónoma de Buenos Aires, Argentina \\ ${ }^{2}$ Cátedra de Patología, Fac. de Ciencias Veterinarias, UBA, Av. Chorroarín 280, Ciudad Autónoma de Buenos \\ Aires, Argentina
}

\begin{abstract}
A 12-year old dog with a 9-year history of primary adrenal insufficiency was referred to the service for hyporexia, muscle weakness, polyuria and polydipsia. Ultrasound examination showed an unresectable mass in the left adrenal gland, with local vascular invasion, which prompted the euthanasia of the animal. Additionally, necropsy revealed a nodular lesion in the right adrenal gland and enlargement of one of the four parathyroid glands. Parathyroid hormone levels were elevated, but ionized and total calcium levels were normal. Histopathology supported the diagnosis of parathyroid chief cell adenoma and bilateral pheochromocytoma. Immunohistochemical staining was positive for synaptophysin, and negative for Melan-A and calretinin, which confirmed the diagnosis of pheochromocytoma. This case highlights an unusual presentation of multiple endocrine neoplasias within the context of primary adrenal insufficiency and normocalcemic primary hyperparathyroidism.
\end{abstract}

Keywords: Hypoadrenocorticism, Parathyroid adenoma, Pheochromocytoma, Synaptophysin.

\section{Introduction}

Primary adrenal insufficiency (PAI), or Addison disease, develops mainly as a result of destruction or immune-mediated atrophy of the adrenal cortex (ScottMoncrieff, 2015). In some isolated cases, PAI is caused by neoplastic invasion of the cortex (Scott-Moncrieff, 2015). Although no causal relationship has been identified, in humans the development of a pheochromocytoma (PCC) in an adrenal gland with PAI was reported by García et al. (2008).

In humans, PCC can develop separately or as part of subtypes $2 \mathrm{~A}$ or $2 \mathrm{~B}$ of multiple endocrine neoplasia (MEN) syndrome (Brandi et al., 2001). In both subtypes it is associated with medullary thyroid carcinoma, and subtype $2 \mathrm{~A}$ also presents hyperplasia or parathyroid adenoma (PA). Although in the dog PCC is usually sporadic (single neoplasm), it has also been reported in the same neoplastic association as that present in the MEN 2A syndrome in two dogs (Peterson et al., 1982; Soler Arias et al., 2016). A case of PCC in association with PA without medullary thyroid carcinoma in a 15-year old Yorkshire terrier was reported by Wright et al. (1995).

Unlike primary hyperparathyroidism, which involves hypercalcemia, normocalcemic primary hyperparathyroidism (nc-PHPTH) is a rare form of hyperparathyroidism only recently described in humans, which presents normal plasma levels of ionized and total calcium, elevated parathyroid hormone (PTH) concentrations and PA, with no secondary cause of hyperparathyroidism (Cusano et al., 2013; Feldman, 2015). In this case, we would like to highlight the unprecedented association of bilateral PCC and PA in the context of nc-PHPTH and longstanding PAI, which is, to the best of the authors' knowledge, the first report in dogs.

\section{Case Details}

A 12-year old female Brittany Spaniel was referred for hyporexia, muscle weakness, polyuria and polydipsia. The animal had been receiving hormone replacement therapy (fludrocortisone and prednisolone) for PAI (Table 1. Diagnosis) since age 3.

The clinical signs on presentation were abdominal tenderness, fever $\left(40.2^{\circ} \mathrm{C}\right)$, tachycardia (164 beats per minute), generalized weakness and progressive weight loss (4 kilograms in 2 years). Biochemical test results showed only increased levels of GPT (141 IU/l, Reference value [RV] : <50 IU/l), GOT (112 IU/l, RV: $<50 \mathrm{IU} / \mathrm{l})$ and SAP (1883 IU/l, RV: up to $300 \mathrm{IU} / \mathrm{l})$ (Table 1). Systolic blood pressure was elevated (190 mmHg, RV: < $150 \mathrm{mmHg}$ [Reusch, 2015]), as measured by impulse oscillometry (petMAP ${ }^{\mathrm{TM}}$ classic, Ramsey Medical, Inc-Tampa, USA).

Chest X-rays were normal. Abdominal ultrasound revealed a mass in the left adrenal gland (confirmed by necropsy, $4 \mathrm{~cm}$ in diameter) with tumor invasion of the abdominal phrenic vein (APV) and caudal vena cava (CVC), which prompted the decision of euthanasia 
(Fig. 1), and a whitish nodule in the right adrenal gland $(0.5 \mathrm{~cm}$ in diameter); macroscopically, thinning of the adrenal cortex was observed (Fig. 2). The left cranial parathyroid gland was enlarged $(0.7 \times 0.6 \mathrm{~cm})($ Fig. 3); accordingly, PTH plasma determination was requested, together with a new assessment of total calcium (preeuthanasia sample). In this last sample, PTH (4.9 pmol/l, VR: 0.6-3.5 pmol/l) was elevated, while total calcium levels were still normal $(2.58 \mathrm{mmol} / \mathrm{l}, \mathrm{VR}$ : 2.25-2.87 mmol/l).

Immediately after humane euthanasia, samples were taken from adrenal, parathyroid, thyroid and pituitary glands. All were fixed in 10\% buffered formalin and stained with hematoxylin-eosin. Histopathologic examination showed the larger parathyroid gland was formed by cubic cells with low-grade pleomorphism, rounded hyperchromatic nucleus and finely granular cytoplasm. Cells formed tortuous trabeculae and packets supported by a delicate fibrovascular stroma with multiple capillaries containing numerous erythrocytes (Fig. 4).

The lesion was consistent with parathyroid chief cell adenoma. In both adrenal glands, the neoplastic tissue showed proliferation of large polyhedral cells with large, acidophilic, finely granular cytoplasm, rounded nuclei with dispersed chromatin and apparent nucleoli. Cells were organized in aggregates, forming irregular packets, delimited by a delicate fibrovascular stroma derived from a thicker fibrous capsule (Fig. 5).

Table 1. Endocrine and biochemical test results.

\begin{tabular}{|c|c|c|}
\hline Diagnosis adrenal insufficiency & Results & $\begin{array}{c}\text { Reference } \\
\text { ranges }\end{array}$ \\
\hline Basal cortisol $(\mathrm{nmol} / \mathrm{l})^{\mathrm{a}}$ & 1.0 & $2.1-58.8$ \\
\hline Post ACTH cortisol (nmol/l $)^{\mathrm{a}}$ & 27 & $65-174.6$ \\
\hline Androstenedione $(\mathrm{nmol} / \mathrm{l})^{\mathrm{b}}$ & 0.34 & $2.4-18.5$ \\
\hline Basal 17-OH (P4) (nmol/l) & 0.4 & $0.09-1.21$ \\
\hline Post ACTH $17-\mathrm{OH}(\mathrm{P} 4)(\mathrm{nmol} / 1)^{\mathrm{b}}$ & 1.9 & $1.5-4.84$ \\
\hline Sodium/Potassium ratio & 21.7 & $>27$ \\
\hline $\operatorname{Sodium}(\mathrm{mmol} / \mathrm{l})^{\mathrm{c}}$ & 135 & $140-155$ \\
\hline Potassium $(\mu \mathrm{mol} / 1)^{\mathrm{c}}$ & 6.2 & $3.6-5.5$ \\
\hline Biochemistry pre-euthanasia & Results & $\begin{array}{c}\text { Reference } \\
\text { ranges }\end{array}$ \\
\hline Urea $(\mathrm{mmol} / \mathrm{l})^{\mathrm{d}}$ & 7.8 & $5.3-16$ \\
\hline Creatinine $(\mu \mathrm{mol} / 1)^{\mathrm{d}}$ & 44 & $<141$ \\
\hline Glucose $(\mathrm{mmol} / \mathrm{l})^{\mathrm{d}}$ & 4.88 & $3.4-6.2$ \\
\hline $\operatorname{Sodium}(\mathrm{mmol} / \mathrm{l})^{\mathrm{c}}$ & 144 & $140-155$ \\
\hline Potassium $(\mu \mathrm{mol} / \mathrm{l})^{\mathrm{c}}$ & 3.6 & $3.6-5.8$ \\
\hline Sodium/Potassium ratio & 40 & $>27$ \\
\hline Ionized calcium $(\mathrm{mmol} / \mathrm{l})^{\mathrm{c}}$ & 1.26 & $1.1-1.4$ \\
\hline Total calcium $(\mathrm{mmol} / \mathrm{l})^{\mathrm{d}}$ & 2.4 & $2.25-2.87$ \\
\hline Phosphorus (mmol/l) ${ }^{\mathrm{c}}$ & 1.45 & $1.0-2.0$ \\
\hline Parathormone 1-84 (pmol/1) ${ }^{\mathrm{a}}$ & 4.9 & $0.6-3.5$ \\
\hline Total calcium $(\mathrm{mmol} / \mathrm{l})^{\mathrm{d}^{*}}$ & 2.58 & $2.25-2.87$ \\
\hline
\end{tabular}

(a): chemiluminescence, (b): enzyme immunoassay; (c): Ionselective electrode; (d): spectrophotometry; (17-OH (P4)): 17 hydroxyprogesterone; $(*)$ : second sample.

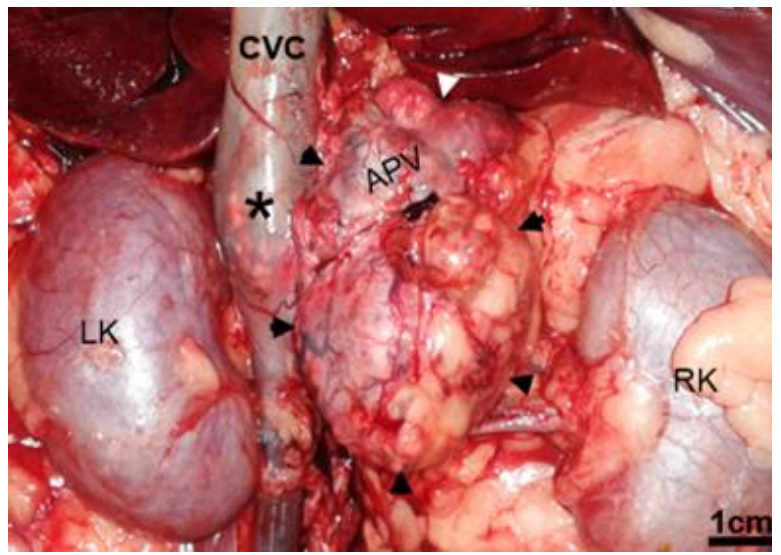

Fig. 1. Left pheochromocytoma (arrows); dog. Neoplastic vascular invasion (asterisk) in caudal vena cava (CVC) and abdominal phrenic vein (APV). Left kidney (LK). Right kidney (RK).

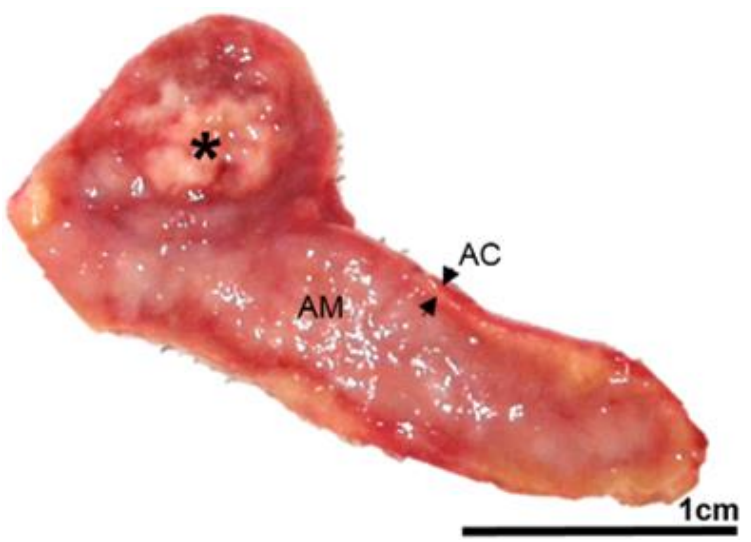

Fig. 2. Right pheochromocytoma (asterisk), sagittal section; dog. Thinning (between arrows) of adrenal cortex (AC). Adrenal medulla (AM).

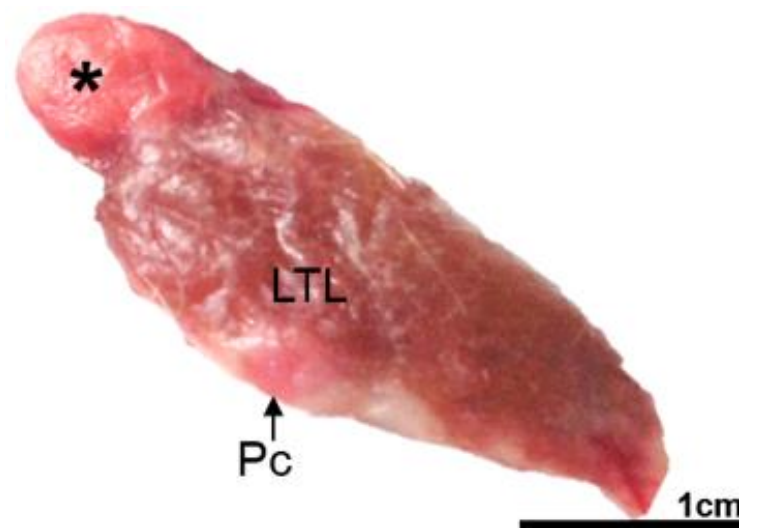

Fig. 3. Parathyroid adenoma (asterisk); dog. Caudal parathyroid gland $(\mathrm{Pc})$ and left thyroid lobe (LTL).

The mitotic index was low (1-3 Figures per 400x field). In the right adrenal gland, in those areas not invaded by the neoplasia, traces of zona glomerulosa with atrophy of zona fasciculata and zona reticularis were observed (Fig. 5, smaller box). The thyroid and pituitary glands were normal in histopathology. 


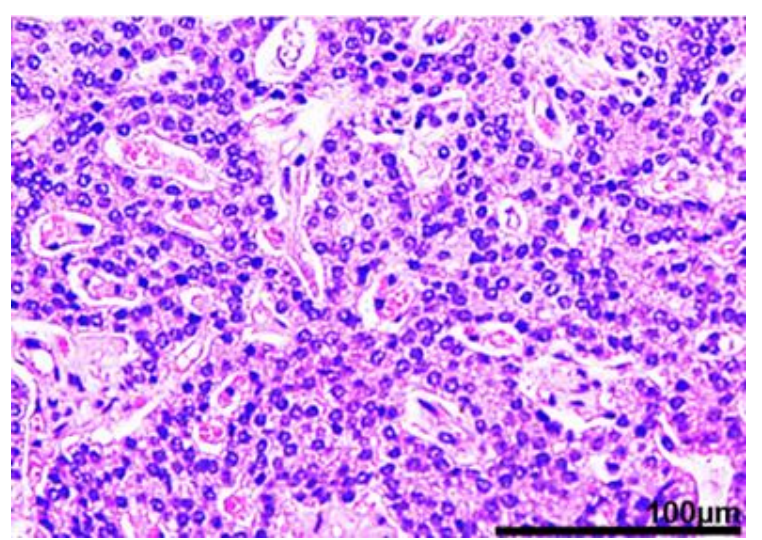

Fig. 4. Parathyroid chief cell adenoma; dog. Section showing cubic cells arranged in tortuous trabeculae and packets supported by a delicate fibrovascular stroma (HE).

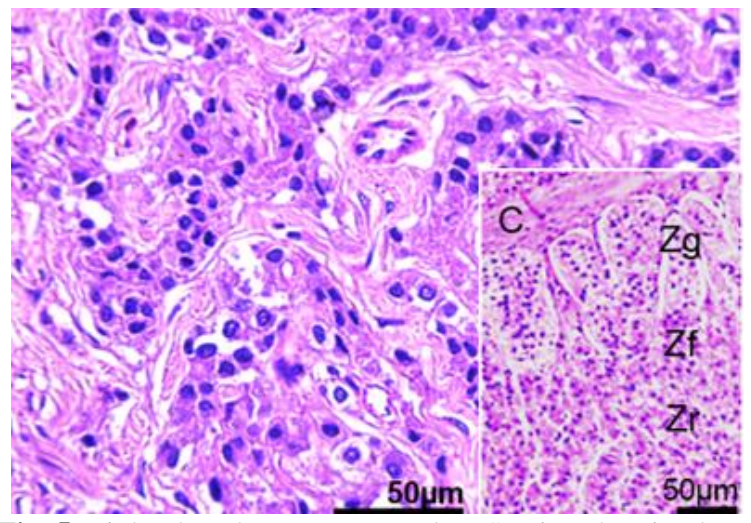

Fig. 5. Right pheochromocytoma; dog. Section showing large polyhedral cells forming irregular packets, delimited by a delicate fibrovascular stroma. HE. Smaller box: section of adrenal cortex not invaded by pheochromocytoma, with traces of zona glomerulosa $(\mathrm{Zg})$ and atrophy of zona fasciculata (Zf) and zona reticularis (Zr). Capsule (C) (HE).

Immunohistochemical procedures were performed in adrenal tissue, using the avidin-biotin complex (ABC) and the immunoperoxidase detection system (Millipore IHC Select $\left.{ }^{\circledR}\right)$, while the chromogen 3.3'diaminobenzidine (DAB) was used for development. The antibodies used are shown in Table 2.

For negative control, the primary antibody was replaced by non-immune IgG (Santa Cruz Biotechnology); for positive control, normal dog adrenal tissue was used. Quantification of the IHC staining was performed semi-quantitatively through the percentage of tumor cells stained positively per field. Staining intensity was subjectively classified as mild, moderate and intense. In more than $90 \%$ of the cells comprising both neoplasias, the cytoplasm was strongly positive to anti-synaptophysin antibody (Fig. 6). Negative staining with melan-A and calretinin ruled out the possibility of adrenocortical origin. On the other hand, lack of staining with anti-chromogranin was attributed to poor neoplastic differentiation.
Table 2. Antibodies used in immunohistochemistry of adrenal tissue.

\begin{tabular}{|c|c|c|c|}
\hline Primary antibody & $\begin{array}{c}\text { Type of } \\
\text { antibody }\end{array}$ & Dilution & Laboratory \\
\hline Calretinin & $\begin{array}{l}\text { Polyclonal } \\
\text { rabbit }\end{array}$ & $1: 200$ & $\begin{array}{c}\text { Santa Cruz } \\
\text { Biotechnology }\end{array}$ \\
\hline Melan-A & $\begin{array}{l}\text { Polyclonal } \\
\text { goat }\end{array}$ & $1: 100$ & $\begin{array}{c}\text { Santa Cruz } \\
\text { Biotechnology }\end{array}$ \\
\hline Chromogranin A & $\begin{array}{l}\text { Polyclonal } \\
\text { goat }\end{array}$ & $1: 100$ & $\begin{array}{c}\text { Santa Cruz } \\
\text { Biotechnology }\end{array}$ \\
\hline Synaptophysin & $\begin{array}{c}\text { Monoclonal } \\
\text { mouse }\end{array}$ & $1: 50$ & $\begin{array}{c}\text { Santa Cruz } \\
\text { Biotechnology }\end{array}$ \\
\hline
\end{tabular}

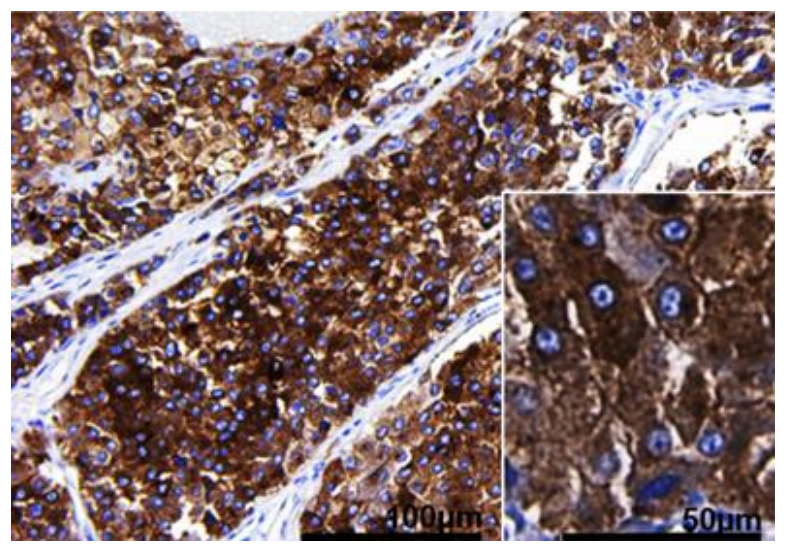

Fig. 6. Left pheochromocytoma; dog. Section showing more than $90 \%$ of cells with positive staining to anti-synaptophysin antibody in histochemical procedures (Avidin-biotin complex). Smaller box: Strongly positive cytoplasmatic staining of neoplastic cells (Avidin-biotin complex).

The histopathologic and immunohistochemical diagnosis of both adrenal lesions was consistent with PCC. The association between bilateral PCC and parathyroid chief cell adenoma in a dog with ncPHPTH and long-standing PAI was confirmed.

\section{Discussion}

Ninety-five percent of cases of adrenal insufficiency in dogs are due to PAI (Scott-Moncrieff, 2015). In the present case, endogenous adrenocorticotropic hormone (ACTH) and plasma aldosterone were not determined, but hyperkalemia and hyponatremia, together with poor cortisol response to exogenous ACTH stimulation test, supported the diagnosis of PAI (Scott-Moncrieff, 2015). Measurement of baseline androstenedione and 17-hydroxyprogesterone before and after the administration of ACTH ruled out congenital adrenal hyperplasia (a form of PAI), since this disorder presents cortisol and/or aldosterone deficiency, but also elevated 17-hydroxyprogesterone and adrenal androgens levels (Castillo and Ortemberg, 2002). Histopathology of the right section of the adrenal cortex (not affected by PCC) was consistent with PAI, since traces of zona glomerulosa and atrophy of zona fasciculata and zona reticularis were found (Scott-Moncrieff, 2015). 
This case, like the one reported by Wright et al. (1995), shares strong similarities with MEN 2A syndrome, but the neoplastic association could not be included in that classification due to the absence of medullary thyroid carcinoma, which in humans shows a $100 \%$ penetrance (Peterson et al., 1982; Wright et al., 1995; Soler Arias et al., 2016). On the other hand, in PCC and PAI report included in human literature, no association was found that could explain the concurrence of both entities (García et al., 2008). In this case, the unusual association of an adrenal mass and PAI observed before the PCC diagnosis suggested the extra-adrenal origin of the neoplasia (metastasis), since coexistence of PCC and PAI had not been reported in dogs. However, since arterial hypertension was associated with an adrenal mass within the context of adrenal cortex destruction, a PCC was suspected. Immunohistochemical staining was strongly positive for anti-synaptophysin antibody (marker for neuroendocrine differentiation) and negative for melan-A and calretinin (adrenal cortical specific markers), which, together with the histopathological characteristics of both lesions, helped confirm the diagnosis of bilateral PCC (Ramos Vara et al., 2001; Zhang et al., 2003; Reusch, 2015). The left PCC was classified as malignant due to local APV and CVC invasion, although no metastasis was observed (Reusch, 2015).

This case, as in 75 to $85 \%$ of dogs with primary hyperparathyroidism, corresponds to a solitary adenoma, larger than $0.5 \mathrm{~cm}$ in diameter, diagnosed based on macroscopic and microscopic appearance, as well as plasma PTH concentrations (Feldman, 2015). Nc-PHPTH was not suspected before euthanasia due to the absence of hypercalcemia, soft tissue calcification or lithiasis. Since at necropsy only one of the four parathyroid glands was increased in size, a PA was suspected (Feldman, 2015). Although ionized calcium and total calcium levels were normal, the increase in size noticed at necropsy and the increase in plasma intact PTH led to the diagnosis of nc-PHPTH (Díaz Guerra et al., 2013; Feldman, 2015). In this case, it was not possible to rule out vitamin $\mathrm{D}$ deficiency as the cause of secondary hyperparathyroidism. However, this last disorder is usually associated with parathyroid hyperplasia in two or more glands, not with a solitary PA (Marchesi et al., 2001; Díaz Guerra et al., 2013; Feldman, 2015). In this case glucocorticoid replacement therapy was considered a possible explanation for normocalcemia, since it can cause a decrease in intestinal calcium absorption and renal reabsorption (Feldman, 2015). In human medicine, ncPHPTH, an entity that has received increased attention in recent years, has been postulated as an early form of hypercalcemic primary hyperthyroidism or as a result of peripheral resistance of tissues to PTH (Cusano et al., 2013).
Finally, we consider the association between PCC and PA could be attributed to a form of MEN specific to dogs, which differs from human subtype $2 \mathrm{~A}$, due to absence of medullary thyroid carcinoma. In relation to nc-PHPTH, since this is the first report in a dog, further studies are needed that correlate levels of intact PTH, vitamin $\mathrm{D}$ and ionized and total calcium in animals with ultrasound evidence of alterations in the parathyroid gland.

\section{Acknowledgements}

We are grateful to Drs. Patricia Vidal and Diego Miceli for their helpful and critical reading of the manuscript.

\section{Conflict of interest}

The authors declare that there is no conflict of interest.

\section{References}

Brandi, M.L., Gagel, R.F., Angeli, A., Bilezikian, J.P., Beck-Peccoz, P., Bordi, C., Conte-Devolx, B., Falchetti, A., Gheri, R.G., Libroia, A., Lips, C.J., Lombardi, G., Mannelli, M., Pacini, F., Ponder, B.A., Raue, F., Skogseid, B., Tamburrano, G., Thakker, R.V., Thompson, N.W., Tomassetti, P., Tonelli, F., Wells, S.A.Jr. and Marx, S.J. 2001. Guidelines for diagnosis and therapy of MEN type 1 and type 2. Endocrinol. Metab. 86(12), 56585671.

Castillo, V.A. and Ortemberg, L. 2002. Addison Disease's in Puppy, Congenital Adrenal Hyperplasia (adrenal 21 Alpha Hydroxilase Deficiency) and Hypoparathyroidism in Dogs. Rev. Cientif. FCV-LUZ, 12(3), 175-181.

Cusano, N.E., Silverberg, S.J. and Bilezikian, J.P. 2013. Normocalcemic Primary Hyperparathyroidism. J. Clin. Densitom.16(1), 33-39.

Díaz Guerra, G.M., Iglesias, S.G. and Carranza, F.H. 2013. Hiperparatiroidismo primario normocalcémico: un problema en aumento. Med. Clin. (Barc), 141(3), 125-129.

Feldman, E.C. 2015. Hypercalcemia and primary hyperparathyroidism, in: Feldman, E.C., Nelson, R.W., Reusch C.E., Scott-Moncrieff, J.C.R. and Behrend, E.N. Canine \& Feline Endocrinology, $4^{\text {th }}$ edi. Elsevier, pp: 579-624.

García, M.T., Apiñániz, E.A., Martínez de Esteban, J.P., Alcuaz, P.M., Goñi Iriarte, M.J. and Llenas, L.F. 2008. Inédita coincidencia: Feocromocitoma sobre glándula suprarrenal atrófica por enfermedad de Addison. Endocrinol. Nutr. 55(10), 510-513.

Marchesi, M., Biffoni, M., Benedetti, R.N. and Campana, F.P. 2001. Incidental Parathyroid Adenomas with Normocalcemia Discovered During Thyroid Operations: Report of Three Cases. Surg. Today 31(11), 996-998.

Peterson, M.E., Randolph, J.F., Zaki, F.A. and Heath, H. 3rd 1982. Multiple endocrine neoplasia in a dog. J. Am. Vet. Med. Assoc. 180(12), 1476-1478. 
Ramos Vara, J.A., Beissenherz, M.E., Miller, M.A., Johnson, G.C., Kreeger, J.M., Pace, L.W., Turk, J.R., Turnquist, S.E., Watson, G.L., Yamini, B. 2001. Immunoreactivity of A103, an antibody to Melan A, in canine steroid-producing tissues and their tumors. J. Vet. Diagn. Invest. 13, 1328-1332.

Reusch, C.E. 2015. Pheochromocytoma and multiple endocrine neoplasia, in: Feldman, E.C., Nelson, R.W., Reusch, C.E., Scott-Moncrieff, J.C.R. and Behrend, E.N. Canine \& Feline Endocrinology, $4^{\text {th }}$ edi. Elsevier, pp: 521-551.

Scott-Moncrieff, J.C.R. 2015. Hypoadrenocorticism. In: Feldman, E.C., Nelson, R.W., Reusch C.E., Scott-Moncrieff, J.C.R. and Behrend, E.N. Canine $\&$ Feline Endocrinology, $4^{\text {th }}$ edi. Elsevier, pp: 521551.

Soler Arias, E.A., Castillo, V.A., Trigo, R.H. and
Caneda Aristarain, M.E. 2016. Multiple endocrine neoplasia similar to human subtype $2 \mathrm{~A}$ in a dog: Medullary thyroid carcinoma, bilateral pheochromocytoma and parathyroid adenoma. Open Vet. J. 6(3), 165-171.

Wright, K.N., Breitschwerdt, E.B., Feldman, J.M., Berry, C.R., Meuten, D.J. and Spodnick, G.J. 1995. Diagnostic and therapeutic considerations in a hypercalcemic dog with multiple endocrine neoplasia. J. Am. Anim. Hosp. Assoc. 31(2), 156162.

Zhang, P.J., Genega, E.M., Tomaszewski, J.E., Pasha, T.L., Virginia, B.S. and LiVolsi, V.A. 2003. The Role of Calretinin, Inhibin, Melan-A, BCL-2, and Ckit in Differentiating Adrenal Cortical and Medullary Tumors: An Immunbasalohistochemical Study. Mod. Pathol. 16(6), 591-597. 